\title{
Analysis and Research on the Tone of Yi Nuo Dialect and Sheng Zha Dialect of Liangshan Nationality
}

\author{
Renqin Yang \\ College of Yi Studies, Southwest Minzu University, Chengdu, China \\ Email:812831372@qq.com
}

How to cite this paper: Yang, R.Q. (2020) Analysis and Research on the Tone of $\mathrm{Yi}$ Nuo Dialect and Sheng Zha Dialect of Liangshan Nationality. Open Access Library Journal, 7: e6701.

https://doi.org/10.4236/oalib.1106701

Received: August 4, 2020

Accepted: August 25, 2020

Published: August 28, 2020

Copyright $\odot 2020$ by author(s) and Open Access Library Inc.

This work is licensed under the Creative Commons Attribution International License (CC BY 4.0).

http://creativecommons.org/licenses/by/4.0/

\begin{abstract}
The Yi language belongs to the Branch of the Tibeto-Burman language of the Sino-Tibetan language family. The Yi language is called $\mathrm{mu}^{33} \mathrm{pi}^{44} \mathrm{do}^{21}$ or $\mathrm{mu}^{33} \mathrm{di}^{44} \mathrm{ho}^{21}$, which means "local dialect". Every dialect area or every place has a different tone. Among the four dialects of Liangshan Yi nationality, Yi nuo and A du dialects are very different from Shengzha and Suodi dialects, especially in tone value. The author mainly selects common words from the two native languages for comparison, analyzes the changes of their tones, and draws the similarities and differences between Yinuo dialect and Shengzha dialect. In Yinuo dialect 33 tones or 35 tones are combined with 35 tones, and the previous one becomes 31 tones. When the two syllables of key 33 are connected, the key value of the previous syllable read out is slightly lower than the latter.
\end{abstract}

\section{Subject Areas}

Linguistics

\section{Keywords}

Yi Nationality, Yinuo Dialect, Shengzha Dialect, Tone

\section{Introduction}

Yi nationality is one of the ethnic groups with a long history and ancient culture in China. It is mainly distributed in Yunnan, Sichuan, Guizhou and northwest of Guangxi. It is mainly distributed in Zhuzhou, Sichuan, and Hongjie. Liangshan Prefecture is the largest Yi inhabited area. Yi people are also distributed in 
Myanmar, Laos, Vietnam, Thailand and other areas (Zhu Wenxu, 2015) [1].

The Yi language belongs to the Branch of the Tibeto-Burman language of the Sino-Tibetan language family. The Yi language branch languages include Naxi, Lisu, Hani, Jinuo, Nusu, Bai, Tujia, and Lahu (Mahai Buji, 2015) [2]. The Yi dialects are divided into six dialect areas, including northern dialects, eastern dialects, central dialects, southeastern dialects, and western dialects, with 26 native languages. Each dialect area has its own name, such as Nuosu, Nasu, Luoluo, Misapo, Sani, Axi, etc. Among them, the northern dialect calls itself "Nuosu", and it is divided into northern sub-dialects and southern sub-dialects. The northern sub-dialects are divided into Shizha Tuyu, Yinuo Tuyu, and Tianba Tuyu, and the southern sub-dialects are divided into Adu Tuyu and Sodi Tuyu. The eastern dialects call themselves "Nasu" and "Nisu", and are divided into the Shuixi dialect (the Qianxi sub dialect, the Bijie sub dialect, and the Dading sub dialect) and the Wu sa dialect (Weining Tuyu, Hezhang Tuyu, Heng Ke Tuyu, Mang Bu Tuyu, Wu Meng Tuyu). The southern dialects call themselves "Niesu" and "Nasu", divided into eastern dialect (Shiping dialect) and southwest dialect (Yuanyang dialect). Southeastern dialects call themselves "Axi”, “Azhe”, "Awu”, "Pula", and "Sani". They are divided into Sani Tuyu, Azhe Tuyu, and Axi Tuyu. The western dialect calls itself "Mi Sapo", with Dongshan Tuyu and Xishan Tuyu. The central dialects call themselves "Luo Luo" and "Lipo", which are divided into Luo Luo Tuyu and Heihei Pu Tuyu. Language is a carrier for spreading culture and a communication tool. Human existence cannot do without language. Languages are all-encompassing and varied, and a nation can have many different dialects and native languages. Language is a symbol of a nation and an important feature that distinguishes it from other nations. Humans use language to convey information. In the early days, the Yi people mainly used Yi language for daily communication. Now, more and more Yi people do not speak the authentic Yi language, and they use it mixed with Chinese. Language is an intangible asset that must be used well while protecting inheritance.

Dialect refers to a local variant of a language, a branch of a common language. Dialects in a certain area are served for the whole people, and as a low-level form obey the high-level standard language form of the common language of the whole people. One language there are many things in common between dialects and dialects, but there are also some special features. These features include phonetics, Language elements such as vocabulary and grammar. Generally speaking, the differences between dialects are expressed in phonetics and vocabulary Is more obvious. The Yi dialect is called $\mathrm{mu}^{33} \mathrm{pi}^{44} \mathrm{do}^{21}$ or $\mathrm{mu}^{33} \mathrm{di}^{44} \mathrm{ho}^{21}$, which means "local dialect" Including the concept of "dialect" also includes sub-dialects and native languages in dialects. Both sub-dialects and native dialects of Yi are used as "XX dialect" or "XX local dialect" refers to sub-dialects and native dialects. For example, the words spoken by the "Shengzha" people in the northern Liangshan dialect are called "Shengzha dialect", and the words spoken by the "Yinuo" people are called "Yinuo dialect". 


\section{The Elaboration of the Concept of Tone}

Tone refers to the change of the height, elevation, curvature and length of the voice. It is an important part of Chinese syllables. Since every Chinese character corresponds to a syllable, tone is also called "Word tone" (syllabic tone). Tone is an important feature of Sino-Tibetan language. Tone includes tone value and tone type. The Chinese tone adopts the "five-degree marking method" proposed by Zhao Yuanren, which divides the pitch of people's normal speech into five degrees, the highest point is 5 , the lowest point is 1 , and the Chinese tone is 55 (Yinping), 35 (Yangping), Shangsheng (214) and Qusheng (51). There are also tones in Yi language, generally three tones, and four tones if you add a secondary tone, but the secondary tone adds similar arcs to the characters in the middle and flat tone. In Yi language, a vertical line is drawn as the standard line from high to low, and then divided into five equal parts, from bottom to top 1 to 5, respectively representing the degrees from low to high. The tone of Yi language is 55 (high flat tone), 44 (secondary high tone), 33 (middle flat tone) and 21 (low flat tone). There are three tones in the "Yi Nuo" native language area, which are 35 (high rising tone), 33 (middle flat tone), and 31 (middle falling tone, 42 high falling tone), without any minor tone (Ma jing. 2013) [3]. There are 4 kinds of dialects in the "Shengzha" area. Differences in pitch indicate changes in the speaker's pitch. According to at first glance the history words and words of tone contrast, we can see at first glance the history's words of tone and words voice, there's a big difference in the tone of the tone value of two languages in terms of considering different tone value, such as the high-profile, words of righteousness there is no time, there are other three voice tone value and history first words is also different, the only one tone is the same, there is level 33. In Yinuo, the key of 33 is slightly lower, close to 22 . When 33 is connected with 33 , the first syllable is slightly lower. When the syllables are connected, there will be a variation of 31 , which must satisfy the condition of $33+35 \rightarrow 31+35$.

There are three tones in Yinuo dialect and four tones in Shengzha Dialect. There is no minor tone in Yinuo, and each tone is not necessarily relative. 55 and 35, 21 and 42 do not correspond to each other, because when reading the historiography in high flat tone, Yinuo does not necessarily read in high rising tone, but may also read in middle flat tone. And when reading the historiography in low falling tone, Yinuo does not necessarily read in high rising tone, but may also read in middle flat tone and high flat tone, depending on the specific words and phrases to correctly pronounce. For example: $f(k o t) \mathrm{ko}^{55}$ basket, Yinuo is pronounced $\mathrm{k}^{33}, \theta$ (vat) $\mathrm{va}^{55}$ wan, Yinuo is pronounced $\mathrm{va}^{35}$.

\section{The Example Analysis}

\subsection{Tone Comparison of Yi Characters and Words}

\begin{tabular}{ccccc}
\hline No. & Yi language & English & Shizhahua & Yinuohua \\
\hline One & $\neq$ & basket & $\mathrm{ko}^{55}$ & $\mathrm{k}^{33}$ \\
\hline
\end{tabular}




\begin{tabular}{|c|c|c|c|c|}
\hline Two & $\sqrt{k}$ & want to & $\mathrm{yo}^{21}$ & $n^{42}$ \\
\hline Three & A & see & $\mathrm{h}^{21}$ & $h^{33}$ \\
\hline Four & (2) & cooked & $\mathrm{mi}^{21}$ & $\mathrm{mii}^{42}$ \\
\hline Five & $H$ & kill & $\mathrm{si}^{55}$ & $\mathrm{se}^{35}$ \\
\hline Six & $\theta$ & wan & $\mathrm{va}^{55}$ & $\mathrm{va}^{35}$ \\
\hline Seven & 조 & cheng & $\mathrm{ti}^{21}$ & $\mathrm{ti}^{33}\left(\mathrm{t}^{33}\right)$ \\
\hline Eight & 匀 & stright & $\mathrm{do}^{21}$ & $\mathrm{do}^{33}$ \\
\hline Nine & $\Psi$ & hand & $10^{55}$ & $10^{35}$ \\
\hline Ten & fNi & Hat umbrella & $\$ u^{55} b u^{21}$ & $\mathrm{du}^{33} \mathrm{bu}^{35}$ \\
\hline Eleven & $\theta$ 打 & dream & $\mathrm{e}^{55} \mathrm{~m}^{21}$ & $\mathrm{e}^{31} \mathrm{~m}^{35}$ \\
\hline Twelve & $\exists \lambda$ & money & $\mathrm{d}^{33} \mathrm{mo}^{21}$ & $d^{33} m^{42}$ \\
\hline Thirteen & 疷 & jumping & $\mathrm{va}^{21}$ & $\mathrm{va}^{33}$ \\
\hline fourteen & $* \theta$ & radish & $\mathrm{va}^{21} \mathrm{ma}^{33}$ & $\mathrm{va}^{42} \mathrm{ma}^{33}$ \\
\hline Fifteen & 隶央 & door & $\mathrm{va}^{21} \mathrm{xa}^{55}$ & $v^{42} \mathrm{xa}^{33}$ \\
\hline Sixteen & 冰寽 & ladle & $\mathrm{va}^{21} \mathrm{lo}^{55}$ & $\mathrm{va}^{42} \mathrm{lo}^{33}$ \\
\hline Seventeen & 拉泜 & socks & $\mathrm{va}^{21} \mathrm{ts}^{33}$ & $\mathrm{va}^{42} \mathrm{ts}^{33}$ \\
\hline Eighteen & 幽出 & pig & $\mathrm{vo}^{55} \mathrm{ba}^{33}$ & $\mathrm{o}^{35} \mathrm{ba}^{33}$ \\
\hline Nineteen & W & The sow & $\mathrm{vo}^{55} \mathrm{mo}^{21}$ & $\mathrm{o}^{35} \mathrm{~m}^{33}$ \\
\hline Twenty & $N \beta N$ & forced & $\mathrm{ti}^{55} \mathrm{l}^{21}$ & $\mathrm{ti}^{31} l \gamma^{35}$ \\
\hline Twenty-one & *综 & The flashlight & $\mathrm{te}^{21} \mathrm{to}^{21}$ & $\mathrm{te}^{33} \mathrm{to}^{42}$ \\
\hline Twenty-two & 话 & dati dance & $\mathrm{ta}^{21} \mathrm{ti}^{55}$ & $\mathrm{ta}^{33} \mathrm{ti}^{42}$ \\
\hline Twenty-three & 邚 & tofu & $\mathrm{tu}^{55} \mathrm{fu}^{21}$ & $\mathrm{tu}^{31} \mathrm{fu}^{35}$ \\
\hline Twenty-four & EN & sheep & $\not \mathbf{D}^{21} \mathrm{mo}^{21}$ & $7^{33} \mathrm{mo}^{33}$ \\
\hline Twenty-five & $\underset{+}{+}$ & cook dry & $\mathrm{to}^{55} \mathrm{~s}^{55}$ & $\mathrm{to}^{35} \mathrm{~s}^{33}$ \\
\hline Twenty-six & $\theta \Re$ & moon & $\mathrm{do}^{21} \mathrm{bo}^{21}$ & $\mathrm{do}^{42} \mathrm{bo}^{33}$ \\
\hline Twenty-seven & $\stackrel{ \pm 灬}{\mathrm{~N} \theta}$ & words & $\mathrm{do}^{21} \mathrm{ma}^{33}$ & $\mathrm{do}^{42} \mathrm{ma}^{33}$ \\
\hline Twenty-eight & 坐 $\frac{11}{1}$ & Tian Kan & $\mathrm{di}^{21} \mathrm{go}^{21}$ & $\mathrm{di}^{42} \mathrm{go}^{33}$ \\
\hline Twenty-nine & 坐弐 & The guest & $\mathrm{di}^{21} \mathrm{vi}^{21}$ & $\mathrm{di}^{42} \mathrm{vi}^{33}$ \\
\hline thirty & 訨最 & master & $\mathrm{vi}^{21} \mathrm{si}^{33}$ & $\mathrm{vi}^{33} \mathrm{si}^{42}$ \\
\hline Thirty-one & Q⿻u从 & under & $\mathrm{o}^{55} \mathrm{to}^{21}$ & $\mathrm{o}^{42} \mathrm{to}^{33}$ \\
\hline Thirty-two & $\vartheta x$ & hat & ${ }^{21} 1^{33}$ & ${ }^{42} 1^{33}$ \\
\hline Thirty-three & Q포 & friend & $\mathrm{to}^{21} \mathrm{bo}^{21}$ & $\mathrm{to}^{33} \mathrm{bo}^{33}$ \\
\hline Thirty-four & $\otimes \mathbb{X}$ & stone & $\mathrm{ti}^{55} \mathrm{lu}^{21}$ & $\mathrm{ti}^{33} \mathrm{lu}^{35}$ \\
\hline Thirty-five & $\Leftrightarrow$ & buckwheat & $\mathrm{yg}^{21} \mathrm{mo}^{21}$ & $\mathrm{ng}^{33} \mathrm{mo}^{42}$ \\
\hline
\end{tabular}

From the above table, we can see the tonal comparison between Shengzha dialect and Yinuo dialect. From it, we find that Yinuo dialect is mainly based on Zhong ping tone 33. If you don't listen carefully, you will feel that what you say is Zhong ping tone. One high and one low fluctuates greatly. The tone value of 35 tones is much lower than the 55 tone of Shengzha dialect. When 33 tones or 35 tones are combined with 35 tones, the tone sandhi will appear, and the syllable of the tone sandhi is the previous one, which becomes the 31 tone 33(35) + 
$35 \rightarrow 31+35$, is the international phonetic symbol marked in red in the table, which is the syllable derived from the phonetic change. For example, the international phonetic symbol of 9 打 $\mathrm{e}^{55} \mathrm{mo}^{21}$, In Yinuo dialect, the original pronunciation is $\mathrm{e}^{33} \mathrm{mo}^{35}$. Because of the above conditions, 31 tones appear when two syllables are connected, so it is pronounced as $\mathrm{e}^{31} \mathrm{mo}^{35}$. This is one of the most important points. When the two syllables of tone 33 in Yinuo dialect are connected, the tone value of the former syllable read out is slightly lower than the latter.

Secondly, according to the comparison of the tones between Shengzha dialect and Yinuo dialect from the above table, it is found that among the three tones 33, 35, 42 of Yinuo dialect, the 33 tones are the most, and many Shengzha dialects read Gao ping tone 55 words in Yinuo dialect have a flat tone or a low tone. I also found that in the two native languages, Yinuo dialect has a lot of changes in the high and low tones of Shengzha dialect. Zhong ping tone is the same. Shengzha dialect has a second high-key tone, but Yinuo dialect does not have this tonal value. Therefore, this tonal value is not reflected in Yinuo dialect. Many people think that the three tones in Yinuo dialect correspond to the tones of 55, 33, and 21 in Shengzha dialect. In fact, this is not the case. A small number of them correspond to each other, but many do not. Because most of Yinuo dialect's tones fluctuate up and down in Zhong ping tone, Shengzha dialect has high and low, and the high-end pronunciation is obvious. This is also one of the phenomena. For example, the Shengzha dialect $N_{N}^{N} N$ is recorded as $\mathrm{ti}^{55}{ }^{21}(\mathrm{He}$ Yaojun. 2008) [4], while the Yinuo dialect is recorded as $\mathrm{ti}^{31} \mathrm{l}^{35}$. Here, the Yinuo dialect has been changed to 33 tones but changed to 31 tones. In Yinuo dialect, the high-level tone 55 is changed to the middle-level tone 33 , and the low-lower tone 21 is changed to 35 high-rise tone. Therefore, the tonal changes in the two native languages are diverse.

Finally, in Yinuo dialect, there is a phenomenon that the joint sound changes and falls off, the initials fall off, and the tone changes, and there is no change. For example, in the above table, $v_{\mathrm{w}}^{\mathrm{w}}$ fat pig is recorded as $\mathrm{vo}^{55} \mathrm{ba}^{33}$ in Shengzha dialect, $\mathrm{vo}^{35} \mathrm{ba}^{33}$ in Yinuo dialect, and $\mathrm{o}^{35} \mathrm{ba}^{33}$ after the initials fall off. The tone is the same as the original.

\subsection{The Tone Comparison of Quantifiers}

\begin{tabular}{|c|c|c|c|c|}
\hline No. & Yi language & English & Shengzha dialect & Yinuo dialect \\
\hline One & s & One & $\mathrm{ts}^{\mathrm{h} 21}$ & $\mathrm{t}^{\mathrm{h} 42}$ \\
\hline Two & ri & Two & $\mathbb{\Delta}^{21}$ & $\bigotimes^{42}$ \\
\hline Three & Iii & Three & $s^{33}$ & $\mathrm{so}^{33}$ \\
\hline Four & $\Psi$ & Seven & 21 & 42 \\
\hline Five & $\theta$ & Wan & $\mathrm{va}^{55}$ & $\mathrm{va}^{35}$ \\
\hline Six & $\Psi \theta$ & seven wan & ${ }^{21} \mathrm{va}^{55}$ & ${ }^{42} \mathrm{va}^{42}$ \\
\hline Seven & f & Ten & $\operatorname{ts}^{h^{h^{3}}{ }^{33}}$ & $\mathrm{ts}^{\mathrm{h}} \mathrm{e}^{33}$ \\
\hline
\end{tabular}




\begin{tabular}{|c|c|c|c|c|}
\hline Eight & s & Hundred & $\mathrm{ha}^{33}$ & $h^{33}$ \\
\hline Nine & Tis & Two hundred & $\mathbb{A}^{21} \mathrm{ha}^{33}$ & $\mathbb{\Delta}^{42} \mathrm{ha}^{42}$ \\
\hline Ten & $\psi$ & Thousand & $\mathrm{du}^{33}$ & $\mathrm{du}^{33}$ \\
\hline Elven & 门嵌了 & Twenty-one & $\nabla^{21} \mathrm{tsi}^{33} \mathrm{ts}^{\mathrm{h} 21}$ & $\nabla^{42}$ tse $^{33} \mathrm{ts}^{\mathrm{h} 35}$ \\
\hline Twelve & $\pi \neq \pi$ & thirty-two & $s^{33} \operatorname{ts}^{h} i^{33} i^{21}$ & $s^{33} t^{h} e^{33} i^{35}$ \\
\hline Thirteen & $f+$ & Fifteen & $\operatorname{ts}^{h} i^{33} n^{33}$ & $\operatorname{ts}^{h^{h} i^{35}} n^{33}$ \\
\hline fourteen & $f \mathbb{N}$ & Fourteen & $\operatorname{ts}^{h} i^{33} 1^{33}$ & $\mathrm{ts}^{\mathrm{h}} \mathrm{i}^{35} \mathrm{l}^{33}$ \\
\hline Fifteen & fii & Thirteen & $\mathrm{ts}^{\mathrm{h}} \mathrm{i}^{33} \mathrm{~s}^{33}$ & $\mathrm{ts}^{\mathrm{h}} \mathrm{e}^{33} \mathrm{so}^{33}$ \\
\hline Sixteen & $5 \theta$ & A & $\mathrm{ts}^{\mathrm{h} 21} \mathrm{ma}^{33}$ & $\mathrm{ts}^{35} \mathrm{ma}^{33}$ \\
\hline Seventeen & $\bigcap_{1}^{1}$ & One kilogram & $\otimes^{21} \mathrm{ti}^{21}$ & $\mathrm{i}^{35} \mathrm{ti}^{42}$ \\
\hline Eighteen & iiv & Six people & $\mathrm{fu}^{55} \mathrm{o}^{55}$ & $\mathrm{fu}^{33} /^{3135}$ \\
\hline Nineteen & $\lim 4$ & Three families & $s^{33} \mathrm{bu}^{21}$ & $\mathrm{so}^{33} \mathrm{bu}^{42}$ \\
\hline Twenty & $\Psi \Psi$ & Sevenyaers & ${ }^{21} k^{h} u^{55}$ & ${ }^{42} \mathrm{k}^{\mathrm{h}} \mathrm{u}^{42}$ \\
\hline Twenty-one & $\Uparrow$ & six years & $f u^{55} k^{h} u^{21}$ & $\mathrm{fu}^{35} \mathrm{k}^{\mathrm{h}} \mathrm{u}^{35}$ \\
\hline Twenty-two & $5 \theta$ & One million & $\mathrm{ha}^{33} \mathrm{va}^{55}$ & $\mathrm{ha}^{33} \mathrm{va}^{35}$ \\
\hline Twenty-three & $\Psi f$ & Seventy & ${ }^{21} \mathrm{c}^{21}$ & ${ }^{33} \mathrm{t}^{\mathrm{h}} \mathrm{e}^{42}$ \\
\hline
\end{tabular}

From the above table, we found that the tone of comparison, history first words righteousness, when reading a falling tone word also have read the falling tone, such as: $\checkmark$ (a), the history of words, the meaning words, history first words reading level of righteousness in the north also has reading level, such as: $\checkmark$ history of (the) first, just words, but some are not the same, history at first in the two kinds of dialect words read the righteousness of high level, the level of, and at first the words read low falling tone in the history of the righteous words in reading level, change, there are many according to each of the corresponding to the actual words. It is found in Qumu Tixi's a Study on The Semantic YiNuo dialect of Yi Nationality that the phonetic change of the combination of quantifiers is more complex and diversified. According to the above actual words, it is found that The Yinuo dialect does have this phonetic change. But there are no such changes in the Vernacular (Qumu Tixi, 2010) [5].

First, the phonetic changes of cardinal numbers. In Yinuo native language, when ften, Thundred, $\Psi$ thousand, and $\ominus$ wan appear after the cardinal number of tone, they are pronounced as tone. Such as $\psi \theta$ (seven thousand), Ii (two hundred). The cardinal numbers of 42 tones become tones when they appear after ften, Shundred, Thousand, $\theta$ wan, such as $\lceil$ 荻 $\checkmark$ (twenty-one), II $f \uparrow$ (thirty-two). $f(+)$ becomes 35 tones when it appears before the cardinal number of 33 tones (e vowels should be loosened to i) $f^{\dagger}$ (fifteen), $f \mathbb{N}$ (fourteen)

The second is the phonetic change of quantifiers combined with quantifiers. The quantifier of the key is usually inconvenient after the cardinal words of 33 and 35, but when 33 and 35 are combined, the former 33 should be changed to 31.42 of the quantifiers in any base word appears behind the inconvenience, but in the presence of 33 adjustable bases behind the words, 33 cardinal Numbers 
into $35 \mathrm{key}$, such as $\pi N i$ (three). 35 of the quantifiers in 42 after cardinal Numbers into 42 adjustable, such as $\Psi *$ (7 years), appeared in 33, 35 unchanged after cardinal Numbers, but in 35 pitch will be turned into 31 cardinal Numbers, such as ii $\Psi$ (six years).

The tones of Yi nuo and Sheng zha are very different. The reason is that Sheng zha area has convenient transportation and exchanges with other areas. Therefore, Sheng zha area is similar to other areas. However, Yi nuo area is not convenient for transportation. I think far away from the surrounding native dialects, so I rarely communicate with each other. Over time, I gradually formed my native dialect.

\section{Conclusion}

A tone is a syllable spelled into a word. The same is true of the Yi language, which is the standard pronunciation of the Yi nationality in Liangshan, just like Mandarin. However, due to the different geographical conditions, transportation, economic and social development in different places, there are different local languages with great differences. There is a distinct difference in tone in the Shengzha dialect, while in the Yinuo dialect the tone is not as high as 55 or as low as 21 . The Shengzha dialect is similar to the local dialect, but different from the Yinuo dialect, mainly in consonants, vowels and tone changes, mostly in tone changes. Therefore, in the analysis and study of Shengzha and Yino dialects, we can start from the tone, and this paper is to analyze from the contrast of tone. Due to the limited amount of knowledge on phonetics at present, there are still many shortcomings in this paper, and the reasons for the change have not been analyzed in detail. In the future, a large number of books on phonetics should be read. Let's solve the corresponding problem.

\section{Conflicts of Interest}

The author declares no conflicts of interest regarding the publication of this paper.

\section{References}

[1] Zhu, W.X. (2015) Dialectics of Yi Language. Central University for Nationalities, Wuhan.

[2] Buji, M. (2015) A Study on the Pronunciation and Vocabulary of the Native Language of the Northern Dialect of Yi Language and a Comparison with Other Native Languages.

[3] Ma, J. (2013) Study of Tonal Modification to Enoch of Northern Dialect. Journal of Bijie University, 32, 34-37.

[4] He, Y.J. (2008) Yi: Chinese Dictionary. Sichuan Nationalities Publishing House, Chengdu.

[5] Qu, T.X. (2010) A Study on the Semantic Nuohua of Yi Language. National Minorities Press, Beijing. 